Usage, Usability, and Utility of 3D City Models, 01001 (2012)

DOI: $10.1051 / 3 \mathrm{u} 3 \mathrm{~d} / 201201001$

(C) Owned by the authors, published by EDP Sciences, 2012

\title{
3D models as a platform for urban analysis and studies on human perception of space
}

\author{
D. Fisher-Gewirtzman
}

Faculty of Architecture \& Town Planning, Haifa 32000, Israel

\begin{abstract}
The objective of this work is to develop an integrated visual analysis and modelling for environmental and urban systems in respect to interior space layout and functionality. This work involves interdisciplinary research efforts that focus primarily on architecture design discipline, yet incorporates experts from other and different disciplines, such as Geoinformatics, computer sciences and environmentbehavior studies. This work integrates an advanced Spatial Openness Index (SOI) model within realistic geovisualized Geographical Information System (GIS) environment and assessment using subjective residents' evaluation. The advanced SOI model measures the volume of visible space at any required view point practically, for every room or function. This model enables accurate 3D simulation of the built environment regarding built structure and surrounding vegetation. This paper demonstrates the work on a case study. A 3D model of Neve-Shaanan neighbourhood in Haifa was developed. Students that live in this neighbourhood had participated in this research. Their apartments were modelled in details and inserted into a general model, representing topography and the volumes of buildings. The visual space for each room in every apartment was documented and measured and at the same time the students were asked to answer questions regarding their perception of space and view from their residence. The results of this research work had shown potential contribution to professional users, such as researchers, designers and city planners. This model can be easily used by professionals and by non-professionals such as city dwellers, contractors and developers. This work continues with additional case studies having different building typologies and functions variety, using virtual reality tools.
\end{abstract}

\section{BACKGROUND}

The current planning policy in many countries is of increasing housing densities. In the USA this policy is part of the New Urbanism ideology, implemented mainly in suburban regions. In Europe, increasing density is one tool of the Compact city ideology, implemented mainly in the intensification of urban environments. In Israel, this concern is due to forecasts of shortage of land in urban areas in the country, with wish to preserve open spaces and natural resources. One approach to preserving these open spaces has been to increase the residential density of urban areas. Currently researchers and planners face difficulties when trying to evaluate the implications of increasing densities on residents' quality of life. Although a fair amount of research was conducted on these issues, there is still a need for a tool that will enable to accurately measure the implications of a certain density level on the residents.

Density measurements are used around the world as a common planning and design tool. Measurements of objective density, such as 'unit per area' or 'built-up area per land area' ratio, do not predict the subjective respond of users, including the perceived density and residents satisfaction of their neighbourhood. The volume of the built-up environment in a specific density can be composed in a variety of spatial configurations. The impact of variant spatial configurations in the same measured density can be completely different regarding the subjective response to the perceived density [17]. Openness to near and distant views influences the quality of life and the environmental quality in a densely built urban environment. The shape of buildings and their positional relationship with each

This is an Open Access article distributed under the terms of the Creative Commons Attribution License 2.0, which permits unrestricted use, distribution, and reproduction in any medium, provided the original work is properly cited. 
other has great influence on the spatial openness to near and distant views. The development of an objective metric that could measure density in the urban environment and at the same time give planners an estimation of the subjective response of people in that built environment is of great importance to our future urban development and research in the field. A preliminary attempt illustrating the great potential [15]. Cullen [8] argued that the environment is perceived by vision and pointed out that vision evokes human memories and experiences that have the power to affect people's minds [7, 8]. Visibility has a strong impact also in Thiel's [27] theory. The visual world for Theil is divided into three-dimensional objects, two-dimensional surfaces, and screens that serve as intermediate elements between objects and surfaces. Several researchers argue that access to an open view has strong impact on people's satisfaction from their surroundings urban environment and their willingness to pay for a view. For example: Feitelson [12] and Oh et al. [24] found that landscape views had a strong impact on determining housing prices. The most desired view for which people were willing to pay more was river, water view, or green mountains. Kfir [21] found that a view from the dwelling units is essential for residents' satisfaction with their environment in artificial islands in Japan. Research reveals that people prefer places with windows than places with no windows, with preference for natural view over a built view, which can influence better health and well-being [19, 20, 30].

Visibility characteristics are an important attribute in high density urban environments and might influence their economic attractiveness. High permeability to view is one of the main objectives in the development of dense urban areas. It can influence the resident's satisfaction and real estate value. In addition, Visual Exposure, referring to privacy, is also a major aspect influencing quality of the humane environment. The 'Spatial Openness Index' (SOI) is a visibility analysis model that is specified in terms of three-dimensional visual spatial information, which is defined as the volume of the visible part of the surrounding sphere. SOI measurement in alternative spatial configurations were correlated with the comparative 'perceived density' [17], thus the objective measurements indicated a subjective response. If designers will acquire knowledge of how to simultaneously preserve low levels of visual exposure and high levels of visual openness to the view for residents in an urban environment, the satisfaction of residents with their urban environment will grow [1, 12, 24].

There has been a revival of interest in visibility analysis of architectural configuration. Some of the current methods and automated models for visual analysis are summarized as follows: An Isovist area is the area directly visible from any location within space. Benedikt [5] was the first to introduce the Isovist and to develop a set of analytic measurements of isovist properties to be applied in order to achieve quantitative descriptions of spatial environment (from [28]). A number of researchers have developed measurement methods and tools for automated 'Isovist' analysis, amongst them Turner et al [29] that showed how a set of isovist can be used to generate a graph of mutual visibility between locations. As a continuation, Turner et al have developed the 'Depthmap' for visibility graph analysis. Batty [4] describes how a set of 'Isovist' forms a visual field whose extent defines different 'Isovist' fields of different geometric properties. He suggested a feasible computational scheme for measuring "Isovist' fields and illustrated how they can visualize their spatial and statistical properties by using maps and frequency distributions. Several models have been developed to examine the Isovist in different ways; The 'Spatialist' by Peponis et al [25] and the 'Axman' by Bin Jiang. Several methods show that visibility is connected to accessibility. For example, the space syntax method [18] examines the relation between spatial configurations and movement, and connects them with social, cultural and economic-functional aspects.

Currently, visibility analysis models for urban systems look at the external space extended from building' facades without concerning the internal space layout. Some analysis models look at facade openings, in a very schematic way, regardless the internal space layout and functionality. Different internal functions and activities demand different levels of privacy and can enjoy different openness to the view. The assumption is that in dwellings the living room and bed rooms require differently levels of privacy and different levels of openness to the view. Also, offices require less privacy regarding external exposure that dwellings. This is of course reliant upon human factors such as culture, society, age, 


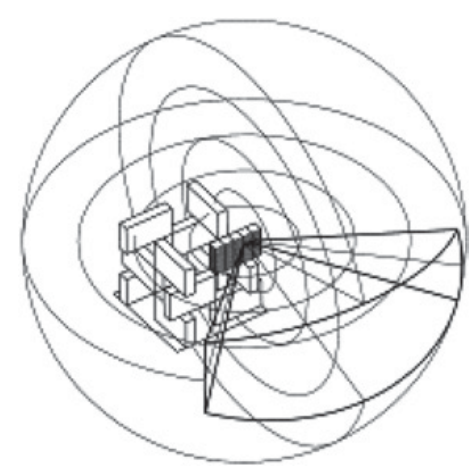

Figure 1. 3D space visible from a dwelling unit.
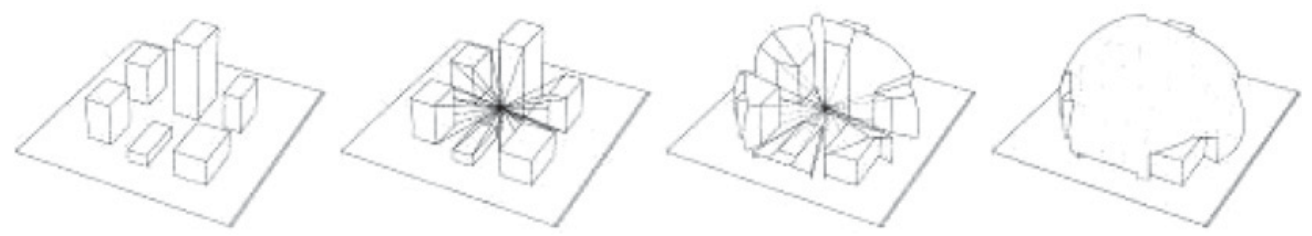

Figure 2. 3D space visible from indicated view point in-between the buildings.

gender etc. Another example is that locating bedrooms indwelling son ground floor may suffer from visual exposure but commerce would enjoy greatly the same exposure. Investigating the internals' space layout and functionality is a major theme and combining space layout and functionality parameters into visual analysis models may contribute to broaden and precise the knowledge in this extremely important field and help support a sustainable urban environment.

\subsection{The Spatial Openness Index}

The Spatial Openness Index can also be described as 3D Isovist. It can explore the 3D visibility and permeability of spatial configurations as illustrated in figure 1 and 2 . It was the first real attempt to simulate human three dimensional visual perceptions [15, 16]. SOI measurements in alternative spatial configurations were correlated with comparative perceived density, thus, the objective measurements indicated the subjective response. The measurements were carried out on alternative abstract configurations with the same volumetric density while participants responded to schematic virtual images. The preliminary SOI model has not been tested on realistic urban environments and was not correlated with residents' subjective respond.

Visual exposure and visual openness may appear to be contradictory terms. The visual openness would be considered as an advantage, insofar as views are longer and further away, and are measured by long distances. Visual exposure, on the other-hand, is defined and measures by short distances. The most dominant attribute found in the literature affecting visual exposure is distance between buildings $[1,10,22]$. Both terms and measures are incorporated in the 'Spatial Openness Index' as illustrated in figure 3.

A preliminary automated model, which enabled the measurement of spatial Openness for alternative configurations within predefined constraints, was developed via the collaboration of architecture and computer science researchers [16]. This automated model enables schematic representation of 3D built environments based on cubic volumes, and the ranking of alternative spatial configurations as illustrated in figure 3. Alternatives are ranked by the measured volume of space potentially observed from every 


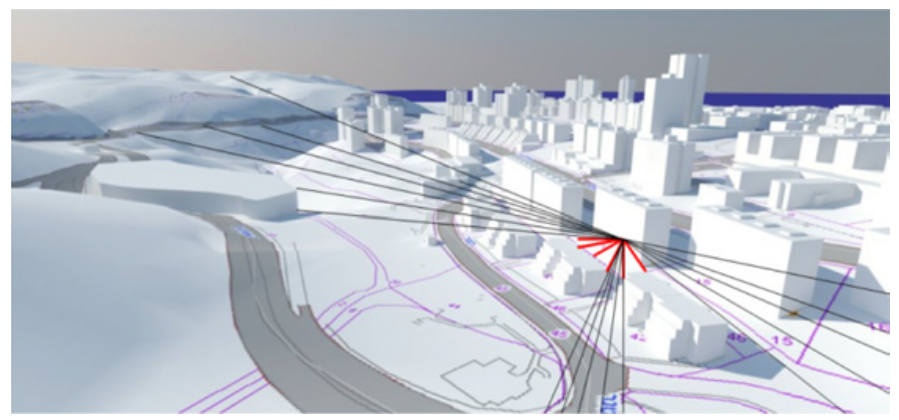

Figure 3. Visual exposure short distance and Visual openness long distances incorporated in the SOI.
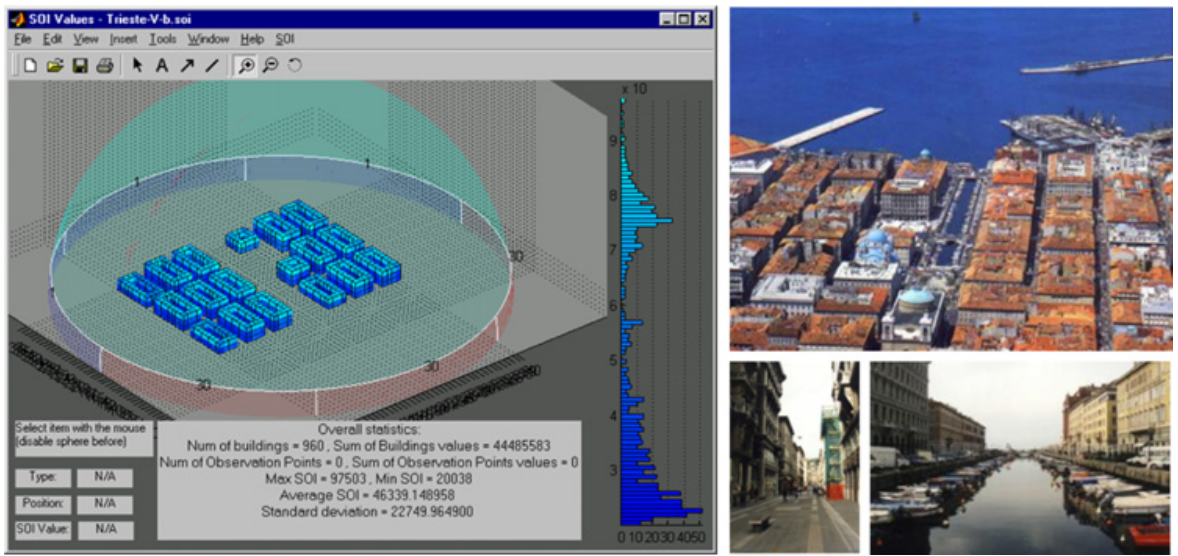

Figure 4. SOI values for urban configuration in the down town of Trieste, Italy. The results are presented numerically and graphically. The volumes are coloured in accordance to their SOI values.

view point located in the centre point of every built cube aimed at measuring the volume of the external visible space. The preliminary automated model was implied on realistic urban environments. Its limitations are the orthogonal geometry configurations and the surface is free of topography thus its ability to represent realism is somewhat limited. Figure 4 is illustrating SOI values for urban configuration in the down town of Trieste, Italy. The results are presented numerically and graphically. The volumes are coloured in accordance to their SOI values.

\subsection{The impact of interior space and functionality}

Existing visual analysis and models and tools for environmental and urban system aspire to examine external space configuration in variant ways without concerning the content and layout of internal space. Figure 5 is illustrating the visual line of sight from each window to all other windows to study the distances and the rate of visual exposure and privacy for each apartment in the building. The analysis is conducted in regard to all openings on the façade. No reference to the function behind the window; is it a private bed room or the kitchen. One of the analysis conclusions was that openings (windows) on the ground level suffer from great visual exposure, meaning privacy disturbances. In the case of dwellings, this is considered negative outcomes.

The assumption is that variant interior space layout and functionality may influence visual analysis since the impact of density, the need for privacy or a nice view are different in variant situations and 


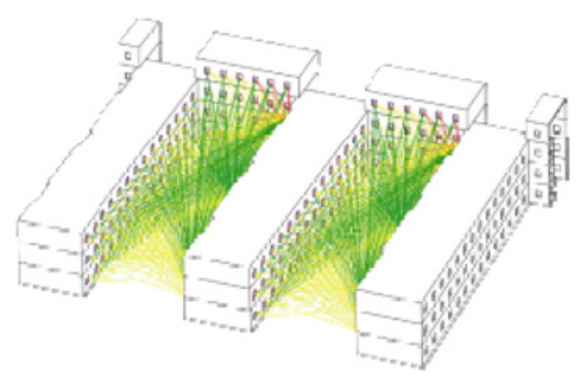

Figure 5. Visual exposure analyses for a dwelling block. The analyses are conducted in regard to all openings on the façade. No reference to apartments' lay-out. [26].

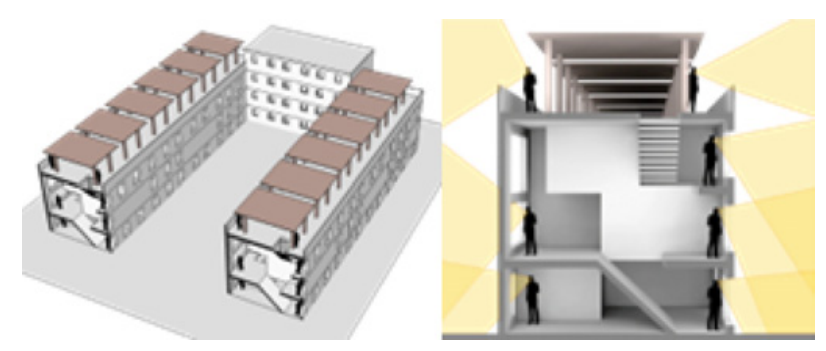

Figure 6. First alternative schematic design: Repetitive vertical apartments providing private entrances on street level, roof-terraces and double protected private spaces located on upper stories.

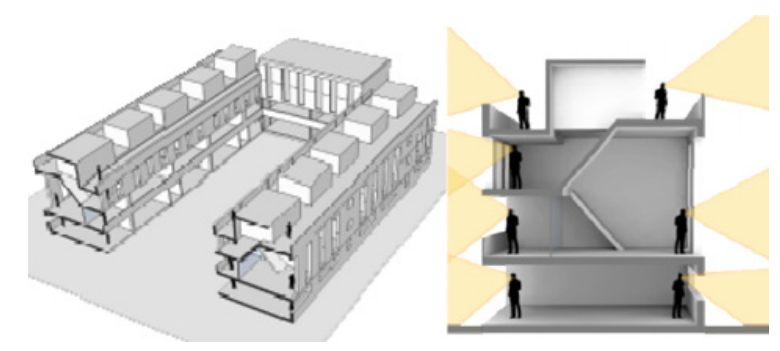

Figure 7. Second alternative schematic design: Repetitive duplex apartments placed on top of a street level public and commercial space. In addition, a roof-public promenade.

different functions. A preliminary study of the impact of variant space layout was conducted on the above case-study. The existing space layout was compared with two alternatives. The existing design is based on repetitive one story apartments, where bedrooms and living-rooms have the same view directions and the same apartments are located on street level and upper levels. The first alternative (as illustrated in figure 6) is based on repetitive vertical apartments. Providing private entrances on street level, roof terraces and double layered protection for private spaces [13, 14]. Entrances on street level do not require privacy and roof terraces are a nice potential to provide a wide view. The functions that demand privacy are located on upper stories and are double protected by layers.

The second alternative, as illustrated in figure 7, is suggesting repetitive duplex apartments placed on top of a street level public and commercial space. In addition, a roof-public promenade [13, 14]. This is a much more social approach. In this case the public and commercial functions on street level require high visibility and accessibility. Roof terrace provides access to the view and the private apartments are located on upper levels therefore are reasonably protected. 
The three variations: the existing design and two alternatives, emphasize that the interpretation of the visual analysis results is not trivial. In some cases they indicate on negative results, in the case of high visual exposure relating to visual privacy in dwelling. At the same time, it could mean very good results regarding visibility and accessibility in the case of commercial space. This highlights the importance of relating to the interior function and layout.

\subsection{Using Geographical Information Systems (GIS)}

Geographical Information Systems (GIS) are computerized information systems, which are characterized by integrated set of tools and applications designed for processing, storing, maintaining, analysing, displaying, modelling and retrieving explicit information that is geographically and geospatially oriented. These working environments are essential to establish natural and man-made environmental processes that require qualitative and reliable management, decision-making and scientific analysis capabilities [9]. GIS has been successfully applied for many years in a wide number of professional contexts, including the fields of planning, engineering, infrastructure, environment, transport, communications, land-ownership, cartography, location-based services, route optimization and more. GIS has traditionally dealt with data in a 2D space, but in recent years there have been significant developments in the direction of three dimensional data handling, modelling, representation and analysis. Community planners, architects, urban designers and land-use planners are increasingly using realistic 3D visualization tools, which now-a-days is characterized under the term of 'Geo Visualization'. 3DGIS is currently utilized mainly for visualization purposes, as well as spatial analysis and planning [23]. Benenson and Torrens [6] showed that Geosimulation via GIS automated modelling of urban phenomena is applicable to model real world complex systems. Combining these tools with planning support systems allows planners and decision makers to interactively change or simulate existing and proposed modelled environments or scenarios in a realistic manner [2].

Data that exist in 3D GIS is usually restricted to exterior geometry and inter-relations of objects (topology), lacking the ability to relate to the interior of the structures and certain attributes that exist in the models. A solution to these problems may lie with utilizing CAD (Computer Aided Design) models as an integrated data source for 3DGIS databases. Via this scheme the external shape, mass and position of the building are well defined, while the internal structure (floors, stairs, rooms, etc.) also exist, thereby providing a functional 3D model for further manipulation and analysis. Another advantage that GIS encompass is the ability to store, analyse and visualize Digital Terrain Models (DTMs) in a native way (Wise, 2010). DTMs are data bases that store data related to position and height of the ground surface topography or terrain, used for producing realistic digital relief maps that enable precise terrainmorphology analysis descriptors. By integrating this type of data to existing 2D or 3DGIS urban data models, one has the ability to produce and analyse a much more realistic and true-to nature environment that is derived from actual topography that exists in the case-study area that is so important for a reliable SOI model [11].

\section{RESEARCH OBJECTIVES}

The purpose of this research work is to develop an integrated visual and quantitative analysis and modelling tool for environmental and urban systems perceptive to interior space layout and functionality. The assessment of such model is carried out in respect to subjective residents' evaluation. The detailed goals that are derived from this purpose are:

- A broader analysis and development of SOI model, to include 3D descriptions and to add a module regarding the interior space layout and functionality.

- To assess the updated model as an analysis tool enabling reliable representation of residents subjective evaluation. 


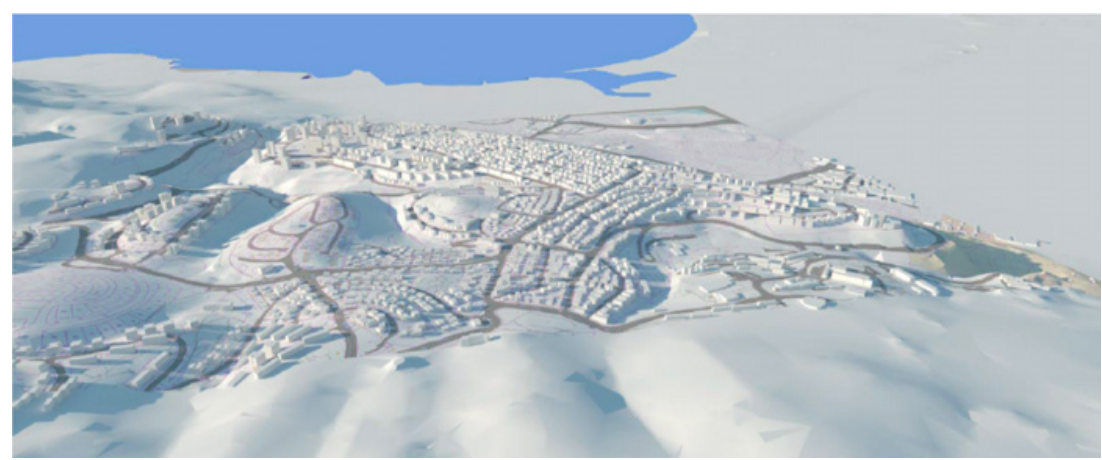

Figure 8. Neve-Shaanan neighbourhood as a case study.

This study aims at comparing the perceived density and ranking of privacy and openness to the view with real-life ranking of residents in an urban neighbourhood, while assessing the ability of the model to predict these measures in planned environments. Objective metric of architectural configuration directing to subjective respond to the design could result in a powerful conceptual model.

\section{RESEARCH METHODOLOGIES}

\subsection{Automated model development}

Detailed description of the current model is presented in Fisher-Gewirtzman, Shashkov and Doytsher, 2012. Visibility is measured by voxels. The algorithm is calculating the number of visible voxels from any indicated view point within a defined urban environment. The size of the voxel is defined by the user. The programming language is c++ and the working environment is Microsoft visual studio 2008. The visual data and the display of the calculation results were implemented using GKUT (Open GL Utility Toolkit). User interface was adjusted to the needs of planners and designers. Demonstration for using the model is displayed on built structures from the case study.

\subsection{Neve-Shaanan neighbourhood as a case study}

The Neve-Shaanan neighbourhood in Haifa was chosen as a case study for this research work. Three reasons for choosing this area:

1. It is a diverse middle class urban neighbourhood.

2. The neighbourhood contains diverse urban structures laid on topography where some have very beautiful distant views.

3. It is very difficult to get cooperation and participation in research questionnaires and even more difficult to get into people homes. Therefore, the public we aim at questioning are students, for their willingness to participate. Most Technion students live in this neighbourhood.

Each participant apartment was represented in detail (windows and interior distribution) in the 3D general model as illustrated in figure 9 and 10. All other structures are represented as volumes that block the view for the examined apartment.

Each apartment was cross checked by the interviewer to see if the interior layout and functions are as in the original plan taken out of the municipality. Exterior views from every room were photographed during the visit. Figure 11 is illustrating the documentation of one of the apartments in the study. The different functions are indicated by their location in the apartment and the external view from each relevant window is documented once by a photograph and by the digital model. In figure 11, the view from window number 1 is very similar in the photography and in the digital image. In window number 3 


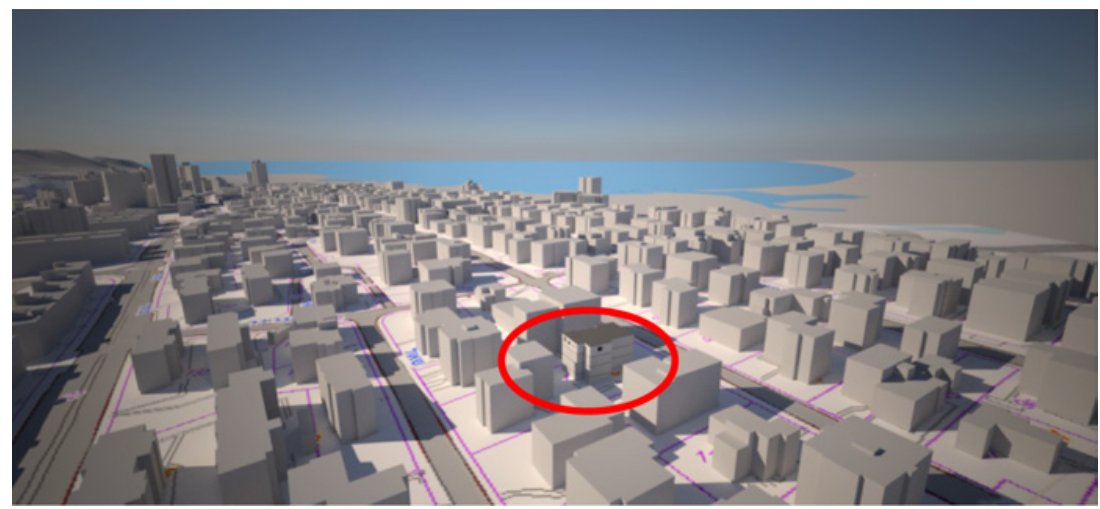

Figure 9. A detailed apartment illustrated within the general model.

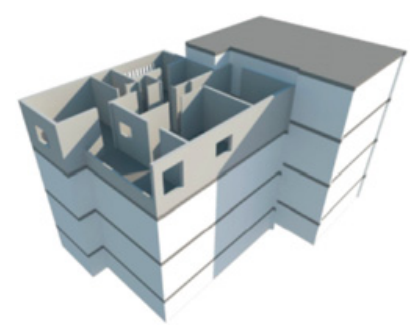

Figure 10. A detailed apartment illustrated within one of the buildings.

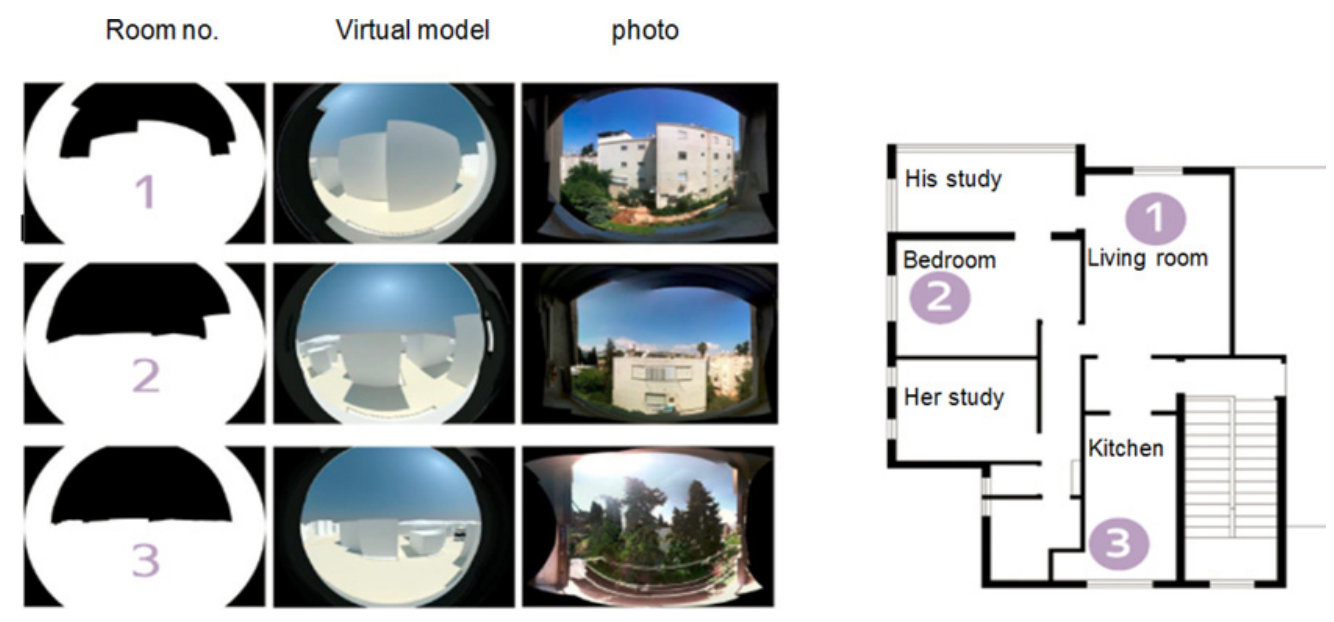

Figure 11. A typical documentation for each dwelling unit being part of the study.

the view is very different in the photography and in the digital model. The tall trees add a very attractive natural sight, create a feeling of privacy towards the opposite buildings and at the same time block the extended view. Such differences that appeared in some cases brought up the need to insert some components of the surrounding vegetation, such as tall and thick trees and to try and learn their impact on perception. 


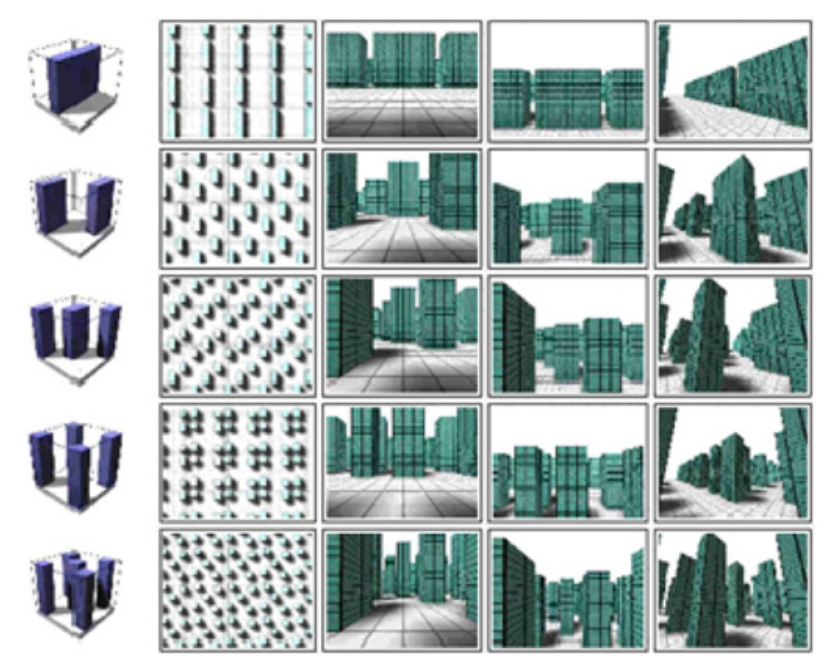

Figure 12. Illustrates part of the information presented to the participants for one of the groups of alternative spatial configurations.

\subsection{Subjective response}

In a precedent research work [17], SOI calculations for the volume of visual space surrounding the built volumes, were correlated with subjective response of participants to the perceived density. The assumption was that spatial configurations with a comparative high level of SOI would be perceived as less compressed and evaluated as more spacious (less dense). To obtain an indication for such correlation, five groups of alternative spatial configurations, all with the identical built-volume, and dispersed within a given volume of space. An approximated SOI was calculated to all alternative spatial configurations, and ranked them within their groups. At the same time participants were asked to rank the alternative configurations by their relative "perceived density".

Architects and students of architecture were asked to participate in this indication test, as it was important that the participants would be able to make the analogy from models and computer representations to real environments. Figure 12 illustrates part of the information presented to the participants for one of the groups of alternative spatial configurations: it represents a basic spatial configuration, an urban fabric and a series of possible views taken within each alternative.

The rank according to SOI calculations and the rank according to subjective response were compared [17]. High correlation was found in three out of the five groups. In the two other groups it was difficult to find agreement amongst participants; therefore very low correlation was found. This indicated on the need to better define the differences between alternative spatial configurations. In the future, using virtual reality machines it would make it possible to invite lay-man participants even for synthetic realities.

In our current research we calculate SOI for a realistic environment represented in a 3D virtual model. The assessment is based on subjective residents' evaluation. Each participant is asked to evaluate their subjective response to the perceived density in their apartment in general and in each of the rooms in the apartments: the living room, the kitchen, their bedroom and study (if relevant). In addition, they were asked to evaluate their visual privacy (are they exposed to external views from their neighbours or passers-by), their openness to the view and type of view outside their windows. This can give us indications as to what are the factors that influence their 'perceived density' evaluation and the objective SOI evaluation. In addition they were asked to report on their general satisfaction from their dwelling environment. We assume all the above have great influence on tenants satisfaction. 


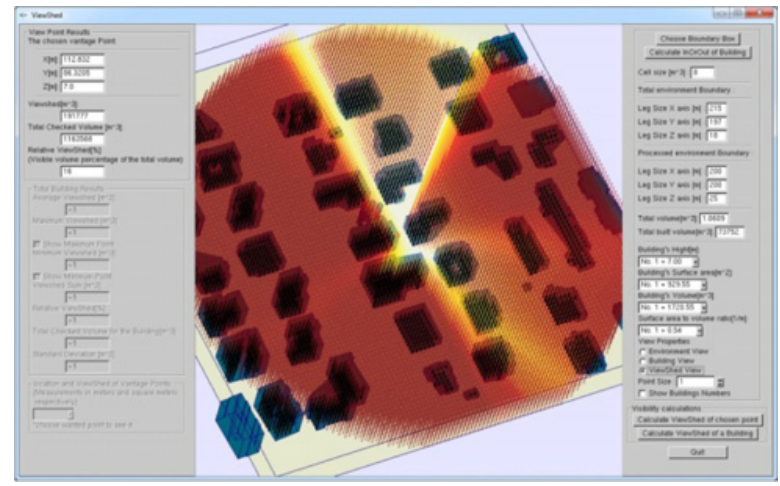

Figure 13. SOI visual analysis conducted on one of the windows of the apartment. Current model updated by Shashkov, Doytsher and Fisher-Gewirtzman.

Table 2 is presenting the format of questions in the questionnaires. Each question was introduced and followed by a table regarding the apartment and each room in the apartment. In some of the cases partners share the same bedroom and some in separate bedrooms. All participants are students that let us enter their apartments. To 'collect' our participants we use the "Snowball" effect, starting from architecture students and their friends, neighbours etc.

The pilot survey was conducted on 5 participants, then extended to 20 participants and is planned to run over 100 participants. We found that sometimes partners that do not share the same bedroom refer to the same external view from their shared living-room differently in accordance to their bedroom view. We also found that gender has influence on questions of privacy. Females evaluate privacy differently than their male partners. To neutralize unwanted factors we need to expand our group of participants.

\section{DEMONSTRATING SOI ANALYSIS AND SUBJECTIVE RESIDENTS' EVALUATION}

SOI current model was developed by Fisher-Gewirtzman, Doytsher and Shashkov (2012). This model has a very friendly user interface. This demonstration is focusing on two apartments. Apartment A is illustrated in figure 11. The apartment is located on the third floor. A young married couple is living there. She is an Architecture student and he is a Low school student. They share all the apartment spaces but have separate studies. Apartment B is shared by two female partners. SOI calculations were conducted for every window in the apartment and both participants were asked (separately) to answer a questionnaire. SOI results and questionnaire outcomes are presented in tables to enable an easy comparison and study.

\subsection{SOI analysis}

We conducted SOI calculations separately for every window in each apartment. The radial visual distance for all calculations was $100 \mathrm{~m}$ '. Figure 13 is illustrating the SOI visual analysis conducted on one of the windows of apartment A. The user interface allows us to choose the resolution and accuracy of calculation, it gives us a 3D representation of the results: the view point is indicated in red and the visual volume of space is lighted and the invisible space within the radius of analysis is illustrated as a dark shadow. This can be examined from any desired direction. In addition, the results are executed and presented as a numerical report of calculations. 
Table 1. SOI results for each room in the apartment A.

\begin{tabular}{|l|c|c|}
\hline Function & SOI calculations buildings only & SOI calculations with trees \\
\hline Bed room $\left(11.9 \mathrm{~m}^{2}\right)$ & 191,777 & 191,777 \\
\hline Living room $\left(15.9 \mathrm{~m}^{2}\right)$ & 95,870 & 95,870 \\
\hline Kitchen $\left(9 \mathrm{~m}^{2}\right)$ & $\mathbf{2 6 0 , 7 7 4}$ & $\mathbf{1 6 2 , 6 1 1}$ \\
\hline (her) study $\left(8.6 \mathrm{~m}^{2}\right)$ & 198,915 & 198,915 \\
\hline (his) study $\left(8.7 \mathrm{~m}^{2}\right)$ & 217,850 & 217,850 \\
\hline
\end{tabular}

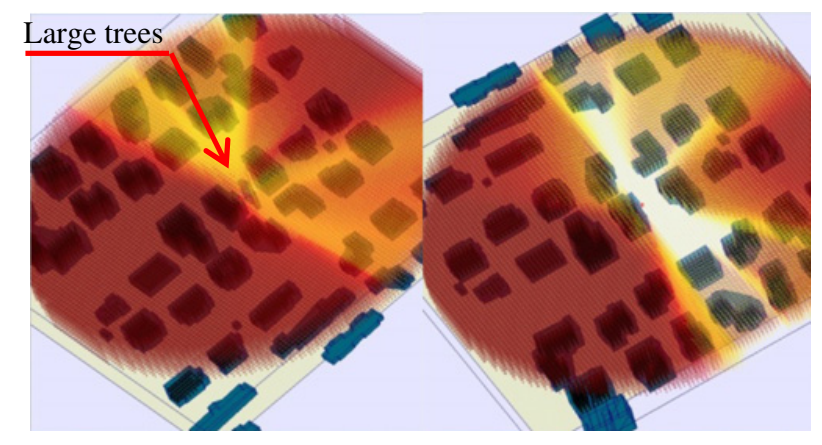

Figure 14. SOI visual analysis illustrating the calculation for the visual space outside the kitchen window, once with the trees and once without.

\subsubsection{SOI analysis for apartment A}

Apartment A is presented in figure 11. Most rooms have one window, 'her' study has two small windows (as illustrated in figure 16), and 'his' study has two large windows (also illustrated in figure 16). The analysis is calculating the volume of visible space from a point placed on a window, therefore does not take into account the size of the window, from which the person may observe the external space. No doubt the size of the window does have some influence on perception.

For the kitchen window (see the photograph in figure 11), we conducted two calculations: Once for surrounding buildings only and once we inserted the trees as objects on sight. This had impact on SOI calculations as illustrated in table 1 . Figure 14 is illustrating the calculation visual outcomes for the visual space outside the kitchen window, once with the trees and once without. The objects representing the trees have great impact on calculation. The difference is visualized very clearly.

All calculations conducted were assembled in table (1) below: for each window separately and for the sum of all windows representing the apartment as a whole.

\subsubsection{SOI analysis for apartment B}

In apartment B, illustrated in figure 15, each partner has a separate room serving as a bed room and a study. They rarely use the hall, therefore it was not considered for SOI analysis. The kitchen and each individual room have two windows each, therefore SOI calculations considered both windows for each as illustrated in table 2.

Participant 1 dwells in the larger room with a terrace. Participant 2 dwell in the smaller room. Both have two windows in two directions. SOI for room 1 is larger than room 2 . The kitchen has the best SOI scores for this apartment. 


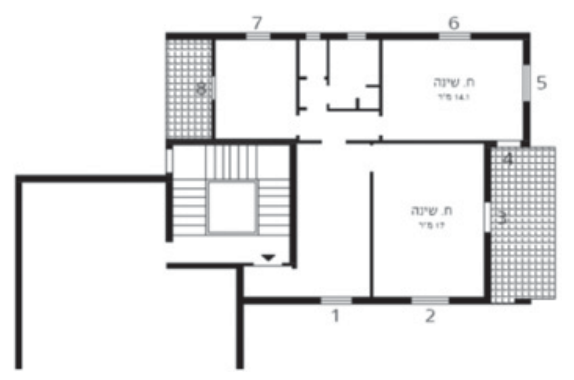

Figure 15. Apartment B.

Table 2. SOI calculations for three relevant rooms in apartment B Participant 1, participant 2 and the common kitchen.

\begin{tabular}{|c|c|c|c|}
\hline Function & Window 1 & Window2 & SOI calculation $\mathrm{m} 3$ \\
\hline $\begin{array}{l}\text { Participant } 1 \\
\text { Bedroom } \\
+ \text { terrace } \\
2 \text { windows } \\
17 \mathrm{~m}+10 \mathrm{~m}\end{array}$ & & & 265,148 \\
\hline $\begin{array}{l}\text { Participant } 2 \\
\text { Bedroom } \\
2 \text { windows } \\
14 \mathrm{~m}\end{array}$ & & & \\
\hline $\begin{array}{l}\text { Kitchen } \\
2 \text { windows } \\
10 \mathrm{~m}\end{array}$ & & & 310,281 \\
\hline
\end{tabular}

\subsection{Assessment using subjective response of the dwellers}

We focus on the question relating directly to the perceived density from each of the relevant spaces in every apartment. The next tables assemble the response of the two partners living in each apartment under review.

Observing both responses: hers and his, we see that the rank they gave to the apartment in general, was the same rank they gave the living room and the bed-room. She ranked them as average density (3) 


\section{European COST Action TU0801}

Table 3. Apartment A: response to the perceived density. Her response (x) his response (y).

\begin{tabular}{|}
\begin{tabular}{|l|c|l|l|l|l|}
\hline What is the density in the spaces indicated below? Her response (x) his response (y) \\
\hline Type of space & 1-very low & 2 & 3 & 4 & $\begin{array}{l}\text { 5-very } \\
\text { high }\end{array}$ \\
\hline Your apartment & Y & & X & & \\
\hline Your living room & Y & & X & & \\
\hline Your kitchen & & Y X & & & \\
\hline Your study & & & Y & X & \\
\hline Your bed room & Y & & X & & \\
\hline
\end{tabular}
\end{tabular}

Table 4. Apartment B: response to the perceived density. First partner (P1) second partner (P2).

\begin{tabular}{|c|c|c|c|c|c|}
\hline \multicolumn{6}{|c|}{ What is the density in the spaces indicated below? First partner (P1) Second partner (P2) } \\
\hline Type of space & 1-very low & 2 & 3 & 4 & 5-very high \\
\hline Your apartment & P1 & & & P2 & \\
\hline Your kitchen & P1 & P2 & & & \\
\hline Your bed room & P1 & & P2 & & \\
\hline
\end{tabular}

and he ranked them as very low density (1). They both ranked the kitchen as low density (2) but since he confirmed using the kitchen very rarely, SOI measurement are not relevant.

The trends of responses are influenced by many factors: the size of the room, its function and the importance/influence/relevance of the view or privacy on the activity in the room, etc. In apartment A, the question relating to the amount of view from each window is the only rank matching the rank of SOI results. All other questions demand a much more complex consideration.

Table 4 presents the response for apartment B. Partner number 1 reported on very low perceived density for all spaces. Partner number 2 reported on medium density for her personal room, low density for the kitchen and high density as general impression from the apartment. Partner number 1 has a larger room attached to a terrace and partner number 2 has a smaller room. The rank by SOI results, partner number 1 has much higher SOI results than partner number 2. Therefore their report regarding density is matching SOI results. Both report on low and very low density in the kitchen. This is absolutely matching the SOI results. From the kitchen windows one may observe the largest volume of space in the apartment.

SOI measurements are objective measurements for the volume of visible space. Subjective responses are complex. In some of the apartments taking part in this study SOI results match the residents' response and in others some differences are found. Observing the differences and interpretation of these participants to our questions reinforces the need for a large quota of participants to understand trends of perception. At the same time, the need to develop a more advanced SOI emerges; measuring the visible space through windows, for a better simulation of reality.

\section{DISCUSSION}

SOI current model enables calculating the potential visible volume of space from each window in realistic environments. In this paper we demonstrated measurement of the volume of potential visible 


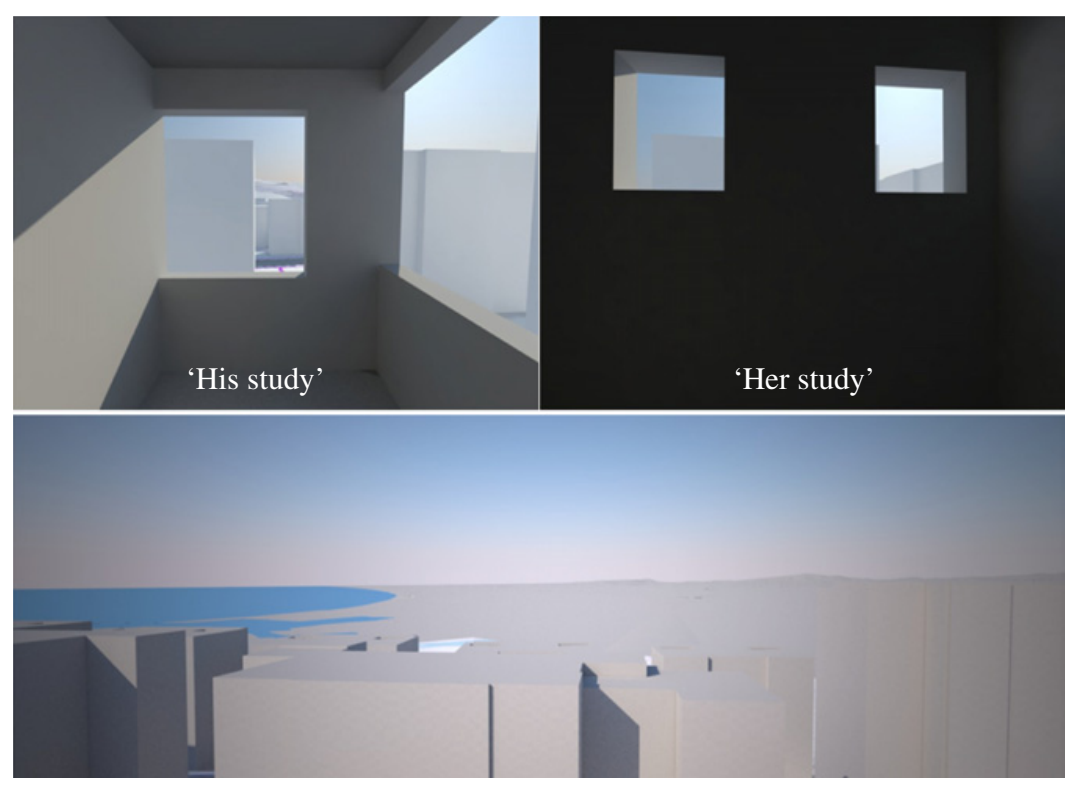

Figure 16. The view from three windows in Neve-Shaanan. Illustrating the view from 'his study', 'her study' and a view from a different apartment. These are some of the controlled views screened to our participants.

space for each window in two apartments in our case-study. In general, calculations were done only for apartments where their residents agreed to take part in subjective response. They were asked about their satisfaction focusing on questions relating to their perceived density, visual privacy and the view. This way we compared between the objective SOI results and subjective response. Out of the two examples demonstrated in this paper, one had very weak correspondence between SOI results and participants evaluations to the perceived density and the other, had perfect matching.

In this paper we tackled the difficulties of subjective response. Assessment using subjective response of residents' evaluation is a complex mission. In the case where each participant lives in a different apartment or even in a different room in the apartment, surrounded by a variety of built structures. A large number of participants will probably neutralize the un-relevant factors and help us point out the significant ones.

The size of the window and its location has great impact on the visualization; therefore we realized the current model does not have the power to express this realistic situation. Therefore the next step for developing the SOI model is locating the point of view inside the space looking out through the window towards the external space. Figure 16 is illustrating this very clearly: The view from three rooms in our case-study is illustrated. On the upper right hand-side, the view is observed from two small windows in a room ('her study', see figure 11). On the left hand-side the view is observed from two large windows ('his study', see figure 11) and the lower illustration is illustrating a view from an open terrace.

Now days we prepare to conduct a parallel study regarding participants' response. All participants are located individually in a controlled environment. In this case participants are immersed in a virtual reality of variant apartments and their external views, as illustrated in figure 17. A 'sketch up' model modified for immersive representation through Indigo renderer software. On the left of figure 17 an internal view looking out is illustrated, and on the right an external urban scene. All participants are exposed to the same views. In this case, circumstances for all participants regarding the spaces projected to them are the same and all the spaces projected are foreign to them; very different from the situation suggested to current participants, where each participant is relating to their own apartment. 


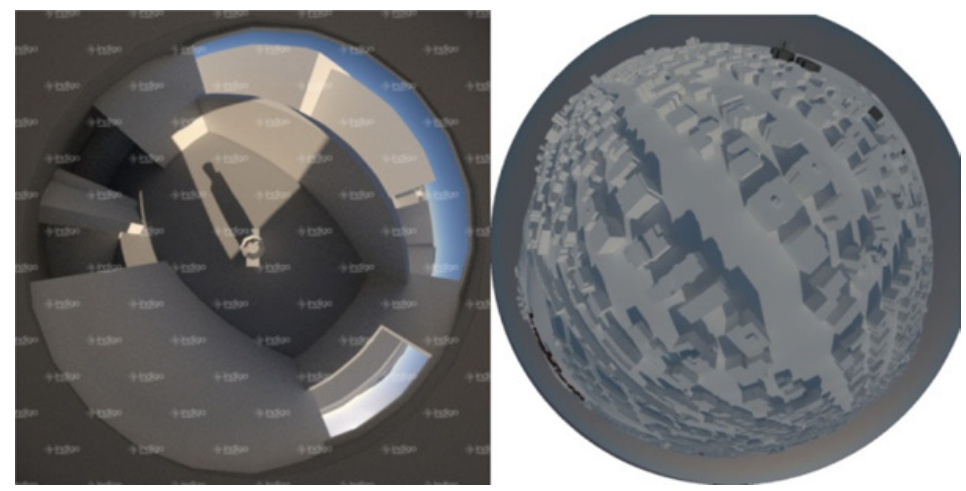

Figure 17. A 'sketch up' model modified for immersive representation through Indigo renderer software. On the left an internal view looking out, and on the right an external urban scene.

The combination of both studies is expected to enlighten the factors influencing visual analysis of environmental and urban systems in respect to interior space layout and functionality.

I would like to thank my colleagues along the years for their contribution to this research: prof. Yerach Doytsher, Dr Sagi Dalyot, Dr Michal Mitrani, prof. Michael Burt, Prof. Yigal Tzamir, and Dr Israel Wagner. To my former student Dr Dalit Shach-Pinsly, my current student Miss Alona Shashkov, and a special thanks to my devoted research assistant: Landscape architect Liran Malka. This research is funded by the Israeli Science foundation (ISF).

\section{References}

[1] Al-Kodmany K., Residential visual privacy: Traditional and modern architecture and urban design, Journal of Urban Design, 4 (3), pp. 283-311 (1999)

[2] Anselin, L., "Spatial Thinking, Exploratory Spatial Data Analysis and Design". Santa Barbara, California: Specialist Meeting on Spatial Concepts in GIS and Design (2008)

[3] Archea, J., The place of architecture factors in behavioural theories of privacy, Journal of Social Issues, 33 (3), pp. 116-137 (1977)

[4] Batty M, "Exploring isovist fields: space and shape in architectural and urban morphology." Environment and Planning B: Planning and design, vol. 28, pp. 123-150 (2001)

[5] Benedikt M L, "To take hold of space: isovist fields" Environment and Planning B: Planning and Design, vol. 6, pp. 47-65 (1979)

[6] Benenson, I., and Torrens, P. M., Geosimulation - Automata-based Modelling of Urban Phenomena, John Wiley \& Sons Ltd, England (2004)

[7] Broadbent, G., Emerging Concepts in Urban Space Design, New York: Van Nostrand Reinhold International (1990)

[8] Cullen, G., The Concise Townscape, The Architectural Press (1971)

[9] Dalyot, S., Keinan, E., Doytsher, Y., Landslide Morphology Analysis Model Based on LIDAR and Spatial Topographic Datasets Comparison. Surveying and Land Information Science (SaLIS), Vol. 68, No. 3, pp. 155-170(16) (2008)

[10] Day L.L., Choosing a house: The relationship between dwelling type, perception of privacy, and residential satisfaction, Journal of Planning Education and Research, 19 (3), pp. 265-275 (2000)

[11] Doytsher, Y., Dalyot, S., and Katzil, Y., Digital Terrain Models: A Tool for Establishing Reliable and Qualitative Environmental Control Processes. In: Geospatial Visual Analytics, NATO Science 
for Peace and Security Series C: Environmental Security, Springer Science and Business Media, pp. 215-234 (2009)

[12] Feitelson E, "Consumers Preferences and Willingness to Pay for Water Related Residence in Non-Urban Setting: A Vignette analysis” Regional studies Vol. 26.1 pp. $49-68$ (1990)

[13] Fisher-Gewirtzman D. "The Visual Openness \& Visual Exposure model in regard to internal space layout and functionality." 3rd ICA Workshop on Geospatial Analysis and Modelling, Gavle Sweden, (2009)

[14] Fisher-Gewirtzman D. "Internal Space layout and functionality as a major aspect influencing Visual analysis for environmental and urban systems" Sustainable city2010, La Curunia, Spain (2010)

[15] Fisher-Gewirtzman D. and Wagner I. A., The 'Spatial Openness Index': an automated model for 3-D visual analysis of Urban Environments, Journal of Architecture and Planning Research, 23 (1), pp. 77-89 (2006)

[16] Fisher Gewirtzman D \& Wagner I, "Spatial Openness as a Practical Metric for Evaluating Built-Up Environments" Environment and Planning B: Planning and Design Vol. 30 issue 1 pp. 37-49 (2003)

[17] Fisher Gewirtzman D, Burt M, Tzamir Y, “A 3D Method for Comparative Evaluation of Dense Built-up Environments" Environment and Planning B: Planning and Design Vol. 30, issue 4, pp. 575-587 (2003)

[18] Hillier B, "Space is the Machine" Cambridge, UK: Cambridge University Press (1996)

[19] Kaplan, R., The role of nature in the context of the workplace, Landscape and Urban Planning, V. 26, pp. 193-201 (1993)

[20] Kaplan, R., \& Kaplan, S., \& Ryan, R. L., With people in mind: Design and management of everyday nature. Washington D.C.: Island Press (1998)

[21] Kfir I. Z., "Research on Residential preferences and the view from the dwelling units on manmade islands in Osaka bay" Submitted in Partial fulfilment of the requirements for the degree of Doctor in Engineering, Department of Architecture and Architectural Systems, Graduate School of Engineering, Kyoto University, Kyoto, Japan (2001)

[22] Merry, S., "Crowding conflict and neighbourhood regulation. In: Altman, I. \& Wandersman, A. (Ed). "Neighbourhood and Community Environments", New York: Plenum (1987)

[23] Nyerges, T. L., and Jankowski, P., Regional and Urban GIS - A Decision Support Approach, The Guilford Press, New York (2010)

[24] Oh K. and Lee W., "Estimating the value of landscape visibility in apartment housing prices", Journal of Architectural and Planning Research, 19 (1), pp. 1-11 (2002)

[25] Peponis J, Winerman J, Rashid M, Bafna S, Hong Kim S, "Describing Plan Configuration According to the Covisibility of Surfaces.” Environment and Planning B: Planning and Design Vol. 25 pp. 693-708 (1998)

[26] Shach-Pinsly D., Fisher-Gewirtzman D., Burt M., "Visual exposure analysis model; a comparative evaluation of three case studies", Urban Design International, Vol. 12, pp. 155-168 (2007)

[27] Thiel P., Visual awareness and design: an introductory program in conceptual awareness, perceptual sensitivity, and basic design skills, Seattle, Wash.: University of Washington Press (1981)

[28] Turner A, "Analysing the visual dynamics of spatial morphology” Environment and Planning B: Planning and Design Vol. 30 pp. 657-676 (2003)

[29] Turner A, Doxa M, O’Sullivan D, Pen A, "From isovist to visibility graphs: a methodology for the analysis of architectural space" Environment and Planning B: Planning and Design Vol. 28, pp. 103-122 (2001)

[30] Ulrich R. S., Simons, R. F., Losito, B. D., Fiorito, E., Miles, M. A., \& Zelson, M. (1991), "Stress recovery during exposure to natural and urban environments", Journal of Environmental Psychology, Vol. 11, pp. 201-230 (1991) http://www.cs.technion.ac. il/ 〜 wagner/pub/so_prog/SpatialOpenness.html 